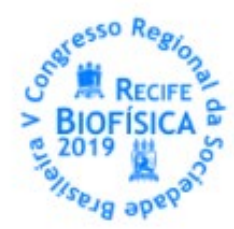

\title{
AÇÃO DE MONOTERPENOS NA ATIVIDADE DE CANAIS DE SÓDIO DEPENDENTES DE VOLTAGEM SUBTIPO Nav1.7
}

\author{
Patrik S. Z. Barbosa1, Brena H. G. Araújo ${ }^{1}$, Wagner M. Faustino ${ }^{1}$, Aliny P. Vasconcelos ${ }^{1}$ Demetrius A. M. Araújo ${ }^{1}$ \\ ${ }^{1}$ Laboratório de Biotecnologia Celular e Molecular, ${ }^{1}$ UFPB \\ patrik.zarp@gmail.com
}

\section{RESUMO}

Introdução: Os monoterpenos são compostos orgânicos presentes em $90 \%$ dos óleos essenciais derivados de plantas, sendo inúmeras as atividades relacionadas a essa classe: efeitos antiinflamatórios, analgésico, anestésico, entre outras, evidenciando aplicações terapêuticas relacionadas à dor. Os canais de sódio dependentes de voltagem amplamente expressos em neurônios nociceptores do gânglio da raiz dorsal (DRG) são essenciais para a eletrogênese de células excitáveis, divididos em nove subfamílias de acordo com as subunidades alfas formadoras de poros, que se diversificam de Nav1.1 a Nav1.9. Destacando-se o Nav1.7 pela alta expressão em neurônios DRG tornando-o um alvo promissor para o tratamento da dor. Nesse contexto, torna-se relevante investigar a atividade de monoterpenos sobre as correntes de Nav1.7. Materiais e Métodos: Os monoterpenos: (-)-carvona, (-)-carveol, carvacrol, limoneno e ()-a-bisabolol foram testados sobre canais Nav1.7 expressos estavelmente em células de ovário de hamster chinês (CHO). As células foram cultivas em frascos de cultura contendo meio DMEM alta glicose suplementado com $10 \%$ de SFB e antibiótico de seleção G418. Os registros eletrofisiológicos de correntes de Nav1.7 foram obtidos por meio da técnica de patch-clamp modo whole-cell. Foi utilizado potencial holding de $-90 \mathrm{mV}$ seguido de um pulso teste de $-120 \mathrm{mV}$ para $0 \mathrm{mV}$ durante $200 \mathrm{~ms}$. Para avaliação da morte celular em neurônios DRG neonatais frente ação dos monoterpenos foram utilizados ensaios de microscopia de fluorescência, analisados qualitativamente, utilizando uma dupla marcação de laranja de acridina e brometo de etídeo ( $\mathrm{AO} / \mathrm{BrTe}-1 \mu \mathrm{g} / \mathrm{mL})$. Foram plaqueadas 400 células por poço, tratadas por $6 \mathrm{~h}$ com os diferentes monoterpenos na concentração de $500 \mu \mathrm{M}$. As imagens foram obtidas utilizando Microscópio Zeiss AX10 (200x). Resultados e Discussão: Os monoterpenos reduziram a amplitude de correntes de sódio em células CHO-hNav1.7. Os valores de densidade de corrente de Nav1.7 na situação controle e na presença dos monoterpenos foram respectivamente: (-)-carvona -21,75 $\pm 2,95$ $\mathrm{pA} / \mathrm{pF}$ para $-17,82 \pm 1,55 \mathrm{pA} / \mathrm{pF}$, correspondendo a uma inibição de 18,07\%; (-)-carveol, $-47,46 \pm 10,76 \mathrm{pA} / \mathrm{pF}$ para $-46,23 \pm 8,62$ $\mathrm{pA} / \mathrm{pF}$, taxa de inibição de 2,59\%; carvacrol $-20,23 \pm 1,66 \mathrm{pA} / \mathrm{pF}$ para $12,81 \pm 1,89 \mathrm{pA} / \mathrm{pF}$, taxa de inibição $36,68 \%$; limoneno $-46,88$ $\pm 9,13 \mathrm{pA} / \mathrm{pF}$ para $-28,58 \pm 7,93 \mathrm{pA} / \mathrm{pF}$, taxa de inibição de $39,04 \%$ e finalmente, (-)-a-bisabolol -27,31 $\pm 5,38 \mathrm{pA} / \mathrm{pF}$ para $-16,65 \pm$ $4,66 \mathrm{pA} / \mathrm{pF}$, com uma taxa de inibição de $39,03 \%$. Foram observados indícios de morte em neurônios DRG neonatais apenas para o grupo tratado com (-)-carvona. Conclusões: Os monoterpenos avaliados modularam os canais de sódio Nav1.7, destacando-se o carvacrol, limoneno e o (-)-a-bisabolol que apresentaram um maior percentual de inibição, com uma taxa superior a 30\%, bem como, não demonstraram níveis elevados de morte celular em neurônios DRG neonatais. Financiamento: CNPq e CAPES. 